\title{
DO WOMEN AVOID SALARY NEGOTIATIONS? EVIDENCE FROM A LARGE SCALE NATURAL FIELD EXPERIMENT
}

\author{
Andreas Leibbrandt \\ John A. List \\ Working Paper 18511 \\ http://www.nber.org/papers/w18511
NATIONAL BUREAU OF ECONOMIC RESEARCH
1050 Massachusetts Avenue
Cambridge, MA 02138
November 2012

The views expressed herein are those of the authors and do not necessarily reflect the views of the National Bureau of Economic Research.

NBER working papers are circulated for discussion and comment purposes. They have not been peerreviewed or been subject to the review by the NBER Board of Directors that accompanies official NBER publications.

(C) 2012 by Andreas Leibbrandt and John A. List. All rights reserved. Short sections of text, not to exceed two paragraphs, may be quoted without explicit permission provided that full credit, including (C) notice, is given to the source. 
Do Women Avoid Salary Negotiations? Evidence from a Large Scale Natural Field Experiment Andreas Leibbrandt and John A. List

NBER Working Paper No. 18511

November 2012

JEL No. C93,J0

\begin{abstract}
$\underline{\text { ABSTRACT }}$
One explanation advanced for the persistent gender pay differences in labor markets is that women avoid salary negotiations. By using a natural field experiment that randomizes nearly 2,500 job-seekers into jobs that vary important details of the labor contract, we are able to observe both the nature of sorting and the extent of salary negotiations. We observe interesting data patterns. For example, we find that when there is no explicit statement that wages are negotiable, men are more likely to negotiate than women. However, when we explicitly mention the possibility that wages are negotiable, this difference disappears, and even tends to reverse. In terms of sorting, we find that men in contrast to women prefer job environments where the 'rules of wage determination' are ambiguous. This leads to the gender gap being much more pronounced in jobs that leave negotiation of wage ambiguous.
\end{abstract}

\author{
Andreas Leibbrandt \\ Department of Economics \\ Monash University \\ Clayton, Vic 3800 \\ Australia \\ andreas.leibbrandt@monash.edu.au \\ John A. List \\ Department of Economics \\ University of Chicago \\ 1126 East 59th \\ Chicago, IL 60637 \\ and NBER \\ jlist@uchicago.edu
}




\section{Introduction}

Around the world, men occupy the highest ranks of society. They rise to become CEOs more often than women, they are more likely to reach the highest positions in government, and they are paid more than women in the labor market. For example, women earn approximately three-quarter's the amount of men's earnings and only $2.5 \%$ of the five highest-paid positions in US firms are occupied by women (Goldin, 1990; Altonji and Blank, 1999; Blau and Kahn, 2000; Bertrand and Hallock, 2001). Social scientists have theorized for decades why this might be the case, with the primary causes being gender differences in human capital (Blau and Kahn, 2000), discrimination against women (Spencer et al, 1999; Goldin and Rouse, 2000), maternal leave (Phipps et al, 2001), and gender differences in competitiveness (Gneezy et al, 2003; Niederle and Vesterlund, 2007; Flory et al, 2010).

There is important laboratory and survey evidence suggesting a quite different determinant of gender differences in labor markets: women are significantly less likely to engage in salary negotiations (Babcock and Laschever, 2003; Babcock et al, 2006; Small et al, 2007). For example, Small et al (2007) observed that in a laboratory experiment men were nine times more likely than women to ask for higher compensation. In important related work, Babcock et al (2006) report labor survey data suggesting that men were eight times more likely to negotiate on salary offers. Finally, Babcock and Laschever (2003) report survey evidence that shows men are four times more likely to negotiate on first salaries and that individuals who do not negotiate first salaries lose more than $\$ 500,000$ by age 60 . Such large gender differences in the willingness to initiate salary negotiations potentially explain a significant fraction of the observed gender differences in wages.

In this study, we depart from a traditional investigation of gender differences by using the tools of experimental economics in the field. Our natural field experiment revolves around placing real job advertisements for administrative assistant positions. That is, we designed our search for administrative assistants around a field experiment to disentangle two important levels where gender differences in negotiation might play a role: (i) sorting into negotiable salary workplaces and (ii) initiation of salary negotiations once the person applies. Our natural field experiment takes place in several actual labor markets in which we observe labor market participants' choices for potentially high stakes without their knowledge of being observed. 
We begin by exploring how two different job advertisements influence the decision to apply-one job advertisement explicitly states that wages are negotiable; the other leaves that aspect ambiguous. This investigation permits us to compare two quite different, but relevant, situations: one which is ambiguously structured so that people arrive with their own interpretations of the situation and one where the negotiations are much more concretely structured. ${ }^{1}$ We proceed to investigate the importance of triggering gender by placing two distinct ads: one for a 'masculine' job task and the other for a gender neutral job. The large sociology and psychology literatures have taught us the importance of sex-based performance stereotypes, and how they cue men and women to behave in predictable ways (see, e.g., Steele, 1997; Bowles et al., 2005). In this way, this design choice moves the exploration of stereotype effects from the lab to the field, and provides a new estimate of how it might trigger behavioral responses to a situation depending on one's socially identified gender (Eagly, 1987).

In total, our job advertisements were posted in nine major US cities. Nearly 2,500 job-seekers responded to our initial job postings. Overall, we find data patterns that share some similarities to the literature. First, we find that when there is no explicit statement that wages are negotiable, men are more likely to negotiate than women. However, when we explicitly mention the possibility that wages are negotiable, women are more likely to negotiate. The first result is consonant with the literature, but we find smaller effects than what is typically reported. Interpreted in light of the meta-analysis of Stuhlmacher and Walters (1999), our tentative conclusion is that in environments in which negotiations are impersonal, gender differences in negotiation play a lesser role than when negotiations are face to face. A tentative implication is that as modern economies evolve, and a greater number of transactions are completed impersonally; gender differences in bargaining might play a lesser role in wage setting.

A second result is that the gender gap in applications is much more pronounced for jobs that leave negotiation of wage ambiguous. Interestingly, this result is driven by men preferring jobs where negotiation of initial wages is ambiguous rather than when negotiations are expected. This result squares well with the literature that

\footnotetext{
${ }^{1}$ This first design choice is in the spirit of the literature, which has shown that the economic structure is an important element affecting bargaining behaviors (Lax and Sebenius, 1986; Neale and Bazerman, 1991; Raiffa, 1982; Thompson, 1998; Walton and McKersie, 1965).
} 
shows that men perform much better than women in environments where negotiations are ambiguous (see Bowles et al., 2005). It is also in accord with psychological theory (e.g. Mischel, 1977), which argues that situational moderators such as ambiguity systematically influence gender differently.

In sum, therefore, we find that women prefer job environments where the 'rules of wage determination' are concrete, and in such settings they are at least as willing to negotiate as men. Alternatively, men prefer environments where the rules of wage determination are ambiguous because it is in those settings where they reap a disproportionate amount of the surplus, relative to women, because they negotiate more than women. Even though we do find some evidence of gender triggering mattering, these findings are independent of the job task and robust to local labor market conditions.

We view these findings as a new piece of evidence on the determinants of wages. Beyond providing an estimate of the importance of gender differences in sorting into the labor market, and actual negotiations upon such equilibrium sorting, our data provide a glimpse at what a world with limited face to face interaction might look like. In this manner, our data suggest that earlier comparative statics on the important variables that shape gender wage differences are evident, but that the modern economy will present women with less of a bargaining handicap than heretofore has been experienced.

The remainder of the paper proceeds as follows. In the next section we present the experimental design. Section 3 reports the experimental findings. Section 4 concludes.

\section{Experimental Design}

To investigate gender differences in job-entry decisions and provide a close link to the relevant theory, we employ a $2 \times 2$ factorial design. Our $2 \times 2$ varies the negotiability of wages (none versus explicit information that wages are negotiable) and the employment advertisement (general versus masculine job task). Our design, which is in the spirit of Flory et al (2010), renders it possible to disentangle the effect of the contract environment on the proportion of initially interested individuals who ultimately apply. 
To carry out the $2 \times 2$, we employ a two-stage experimental method. In the first stage we advertise the administrative assistant position, without reference to the contract environment. In the second stage, after job-seekers express interest in the position, we inform them of the contract environment and record whether they ultimately choose to apply for the job. These two steps are important because they allow us to randomize contract environment across subjects without affecting the normalcy of the field setting. An additional benefit is that we can collect individual characteristics even on those subjects who expressed interest but ultimately chose not to apply after they were informed about the contract environment.

We posted 18 job ads in nine major US metropolitan areas (Atlanta, Dallas, Denver, Houston, Lost Angeles, Portland, San Francisco, San Diego, and Washington DC) with different local labor market conditions. The ads were posted in city-specific internet job-boards in the period of November 2011 - February 2012. At the end of the experiment, we offered real jobs to applicants in every city. Ten applicants were actually hired.

\subsection{Contract environment treatments}

We investigate the role of ambiguity for gender differences (Mischel, 1977; Bowles et al, 2005) in the context of salary negotiations by comparing job-seeker behavior in two contract environments. Within each given city, we randomized jobseekers who expressed interest in the position into one of two contract environments, i.e. treatments (denoted as T1, where wages were not explicitly advertised as negotiable, and T2, where wages were explicitly advertised as negotiable). Subjects were only given the treatment after they had already expressed interest in the job, and they received the treatment usually within two days of expressing this interest. In both treatments, job-seekers received information about the wage of the advertised job. The posted wage (usually $\$ 17.6 /$ hour) ${ }^{2}$ was identical across job ads and slightly higher than the median wage for comparable jobs in most cities. To manipulate the level of ambiguity about wage negotiations in a clean manner, the only difference between the two treatments is whether we explicitly mentioned that the wage is negotiable. The scripts for both treatments are listed in Appendix A.

\footnotetext{
${ }^{2}$ See Appendix B for more information on posted wages.
} 
We were careful in the emails to create an environment as natural as possible, where we were open to questions, apologizing for any questions about the job they may have asked to which we have not responded, and welcoming further inquiries. To avoid heterogeneous treatment we did not interact with job-seekers until they decided to apply.

\subsection{Employment advertisements}

To test the relevance of sex-based performance stereotypes for salary negotiations (Steele, 1997), we posted in each of the nine cities two openings for administrative assistant positions. One ad was for a 'general' ('gender-neutral') version of the job, and the other for a more 'masculine' version. We chose to include a masculine version as women may feel at a disadvantage and less efficacious in masculine job tasks (Beyer, 1990) and thus be more likely to avoid negotiations when applying for such job tasks. In addition, it seems likely that the two positions attract different types of job-seekers and that the masculine version attracts a higher fraction of men. The job ad for the gender-neutral position was looking for administrative help with fundraising. The job ad for the masculine position was looking for someone helping with administrative assistant duties in an environment heavily focused on sports (basketball, football, baseball, soccer, Nascar, golf, tennis, hockey).

The advertisements resembled other ads for similar positions and identified who we were, where we were located, and said that we were looking for an administrative assistant in their area. The job ads can be found in Appendix A. ${ }^{3}$ The advertisement ended with a single sentence requesting interested job-seekers to email their $\mathrm{CV}$ or resume. The advertisement was signed from a current employee of our organization.

We chose administrative assistant positions for several reasons. First, administrative assistant positions are the most common occupation in the US (13\% of the workforce). ${ }^{4}$ Second, such jobs can be relatively easily created, and thus we could offer real positions to some of the job applicants. Third, we could set up remote tasks

\footnotetext{
${ }^{3}$ We chose to identify explicitly a genuine organization to minimize any risk of suspicion. Having a genuine employee of the organization sign off the email added further insurance, should any jobseekers wish to do a brief internet search to verify the ad's authenticity.

${ }^{4}$ Bureau of Labor Statistics Employment and Earnings, January 2010, Vol. 57(1). Available online: http://www.bls.gov/opub/ee/empearn201001.pdf.
} 
that can be performed with an internet connection such that we could study impersonal negotiations in labor markets in different cities. ${ }^{5}$

\subsection{The response variables and job-seeker characteristics}

We are interested in the individual decision of whether or not to apply, and whether or not to negotiate. Our subject pool consists of every individual who contacted us to express interest in the job. In order to actually apply, however, the interested job-seeker had to fill out the interview questionnaire and send it back to us. We, therefore, classify all subjects who returned the questionnaire to us as having applied, and those who did not return the questionnaire as having not applied. In the interview questions we checked whether job-applicants asked for a higher wage or not. Typical cases of negotiation were: “The wage of $\$ 17.60 / \mathrm{hr}$. does not really meet my expectations. My desired wage would be closer to $\$ 20 / \mathrm{hr}$ ", “The wage is good, although my minimum is usually $\$ 19-\$ 21$ per hour. I have 20 years of comprehensive admin experience to offer", or "my desired wage is $\$ 21 / \mathrm{hr}$, but I am open to negotiation".

In order to determine gender and not disrupt the normalcy of the field setting, we use each subject's first name and employ a three-tier method. ${ }^{6}$ For the vast majority of names we use the Social Security Administration (SSA) database on name popularity by gender and birth year to assign gender based on probabilities. ${ }^{7}$ For names that are not included in the SSA database, we use an additional database (available at http://www.gpeters.com/names/baby-names.php), which calculates gender ratios by first name, using the internet to analyze patterns of name-usage for over 100,000 first names. We also use this second database as an additional check on the SSA-based assignments in cases where the gender ratio derived from the SSA database is too low to confidently assign one gender or the other. Finally, for all

\footnotetext{
${ }^{5}$ One drawback of using administrative assistant positions is that they are mainly occupied by women (79\%), and thus may make extrapolations to other jobs difficult where the gender distribution is significantly different.

${ }^{6}$ Note that directly asking for gender could have altered the subject's decision of whether or not to apply and it also has important legal implications.

${ }^{7}$ We use the SSA database to calculate a weighted gender probability for each first name. The database reports figures on the most common 1,000 names for men and women born in any given year. We take a given name, proceed to use the number of men and women born each year with that name, and then create a gender ratio for that name in each given year. We then look across multiple years to create a weighted average of this gender ratio. A more detailed description of the procedure can be found in Flory et al (2010).
} 
names where neither database yields a large enough gender ratio to make a confident assignment, we perform internet searches for gender identifiers of the actual subjects themselves, e.g., by finding the subjects on social networking websites.

The remaining individual characteristics of interest (level of education and job experience; i.e., whether a job-seeker has already worked as administrative assistant) were gathered from the resumes sent to us by the subjects.

\section{Experimental Results}

We report data from all 2422 job-seekers who signaled interest in our job ads. ${ }^{8}$ We could identify gender from 2382 out of the 2422 job-seekers. Overall, 36.2\% ( $\mathrm{n}=863$ ) filled out the application questionnaire and decided to apply. $16.3 \%$ of these job-applicants negotiated on the wage $(n=143)$. Approximately two-thirds of the jobseekers are female $(n=1590)$. We achieved our goal to attract different job-seeker pools for the two job ads as we observe that the gender distribution depends significantly on the job ad. For the job ad with the neutral job-task, 78.7\% are female $(n=930)$ whereas for the job ad with the male job-task only $55 \%$ are female $(n=660$; Fisher exact test $\mathrm{p}<0.001)$.

The job-seekers were randomized into treatments T1 $(n=1187)$ and T2 $(n=1195)$, in which we varied whether wages were explicitly negotiable. Overall the application probability is almost identical across treatments (Fisher exact, p>0.701). In T1, where wages were not explicitly advertised as negotiable, $36.7 \%$ applied. In T2, where wages were explicitly advertised as negotiable, $35.8 \%$ applied. Table 1 shows the number of observations and application probabilities for the job ads posted in the nine different cities.

\section{TABLE 1 ABOUT HERE}

\section{Sorting into jobs with negotiable wages}

Figure 1 illustrates the application probabilities depending on treatment and gender. First, we observe that women are overall less likely to apply than men $(32.5 \%$ vs. $43.8 \%$, Fisher exact, $\mathrm{p}<0.001)$. Second, interestingly, the gender gap in application

\footnotetext{
${ }^{8}$ For completeness, these data include pilot and non-pilot data. In the Appendix B we exclude data from job ads that may be considered as pilots and show that our findings are robust to this exclusion.
} 
probabilities is more pronounced in T1 than in T2. In T1, women's application probability is $31.9 \%$ and men's application probability is $46.6 \%$. In contrast, in T2, women's application probability is slightly higher (33.0\%) whereas men's application probability is slightly lower (41.2\%). Thus, the gender gap almost halves (from $14.7 \%$ to $8.2 \%$ ) when moving from $\mathrm{T} 1$ to $\mathrm{T} 2$.

\section{FIGURE 1 ABOUT HERE}

In Table 2 we present three logit models with the decision to apply as the dependent variable. The first model uses as controls only treatment, gender, the interaction treatment $\times$ gender and city fixed effects to account for different application probabilities across cities. Model (2) controls in addition for the job task (masculine or gender neutral), and the interaction treatment $\times$ job task. Model (3) makes use of two variables indicating the job-seekers qualifications (education and job experience), and their interactions with treatment.

We observe that the T2 $x$ gender interaction is marginally significant at $\mathrm{p}<0.1$ taking into account city fixed effects (model 1) and significant at $\mathrm{p}<0.05$ in models (2) and (3). This provides evidence that women are not more but less likely than men to sort out of workplaces that explicitly offer negotiable wages. The effect size is economically large: The gender gap in application probabilities shrinks by $6.2-8.7$ percent in application probabilities which is approximately $17-24 \%$ of the mean overall application probability. Models (2) and (3) also show that application probabilities from men are higher for the sports job ad (variable: job task), and that men's willingness to enter workplaces with explicitly negotiable wages as compared to workplaces without explicitly negotiable wages is higher for the sport job ad (variable: treatment $\times$ job task). Model (3) shows that job-seekers with at least a bachelor degree are significantly more likely to apply than those with lower education.

Interestingly, we also observe that the $\mathrm{T} 2$ dummy is significantly negative in all three models showing that men are more likely to apply in $\mathrm{T} 1$ than $\mathrm{T} 2(\mathrm{p}<0.1)$, and that the coefficient of the T2 dummy is larger (more negative) and more significant $(\mathrm{p}<0.05)$ after controlling for the T2 $\mathrm{x}$ sports ad interaction showing that men in particular avoid T2 when the job task is general. The men's preference for contract environments that leave wage negotiations ambiguous is well in line with 
psychological theory (Mischel, 1977) and complements survey evidence on salary negotiation performance suggesting that men receive a higher salary than women especially when negotiations are ambiguous (Bowles et al, 2005).

\section{TABLE 2 ABOUT HERE}

Figure 2 illustrates the application probabilities depending treatment and job task. This figure shows that the gender gap in application probabilities decreases when going from $\mathrm{T} 1$ to $\mathrm{T} 2$ regardless whether the job task is neutrally framed (general job advertisement) or in favor of men (sports job advertisement). We view this is an additional piece of evidence suggesting the robustness of our previous finding.

\section{FIGURE 2 ABOUT HERE}

Appendix Figure A complements Figure 1 and illustrates the application probabilities depending on treatment and gender in nine different US cities in which the job ads where placed. Figure A shows that there are differences in application probabilities across cities but that the patterns when moving from $\mathrm{T} 1$ to $\mathrm{T} 2$ are similar across genders in a given city. There is no city where males' application probabilities increase and at the same time females' application probabilities decrease when moving from T1 to T2. In contrast, in Atlanta, Denver, and San Diego males' application probabilities decrease from $\mathrm{T} 1$ to $\mathrm{T} 2$ whereas females' application probabilities increase. This suggests the robustness of our previous finding that women are not less likely to sort out of negotiable employment contracts.

Result 1: Women are less likely than men to sort out of workplaces that offer explicitly negotiable wages. Men prefer workplaces where negotiation of initial wages is ambiguous.

\section{TABLE 3 ABOUT HERE}

\section{Wage Negotiation}

We continue with the analysis of the actual willingness to negotiate wages. Are women less likely to negotiate on wages? First, we observe that our treatment manipulation has successfully induced negotiations. Indeed, there are large and 
significant treatment differences in the probabilities of negotiation initiations (Fisher exact, $\mathrm{p}<0.001$ ). In $\mathrm{T} 2$, negotiations occurred approximately 2.5 times more often than in $\mathrm{T} 1.23 .1 \%$ of the job-applicants started to negotiate on the wage in $\mathrm{T} 2$ whereas only $9.4 \%$ in $\mathrm{T} 1$.

\section{FIGURE 3 ABOUT HERE}

Figure 3 illustrates the negotiation probabilities depending on treatment and gender. This figure shows a slight reversal in negotiation probabilities across treatments. In T1, where there was no explicit information that wages are negotiable, women are less likely to negotiate than men ( $8.2 \%$ vs. $10.6 \%)$. This difference is consonant with meta-analysis findings (Stuhlmacher and Walters, 1999) suggesting that men's relative to women's higher propensity to negotiate is less pronounced when negotiations are impersonal than when they are face to face. However, in T2 where we explicitly mentioned the possibility that wages are negotiable, women are more likely to negotiate ( $23.9 \%$ vs. $22 \%)$.

In Table 3 we present three logit models with the decision to negotiation as the dependent variable restricted to the sample of job-applicants. These three models correspond to the three models in Table 2. We observe in all three models that the treatment $\times$ gender interaction is positive and sizeable. The negation probability increases by $5.9-6.1 \%$, which is substantial given an overall mean negotiation probability of $23.1 \%$. However, given the relatively small sample size this interaction is not yet significant at conventional levels $(p>0.252)$. Thus, we cannot say with confidence that women are more likely than men to initiate wage negotiations but we can clearly reject the opposite.

Appendix Figure B illustrates the probability of negotiations depending on treatment, gender, and city. While the number of observations is rather small in some cities, it is interesting to observe that there are four cities in which men negotiate more than women in T2 (DC, Denver, Los Angeles, and Portland) while women tend to negotiate more in $\mathrm{T} 2$ in the remaining five cities (Atlanta, Dallas, Houston, San Francisco, and San Diego).

Figure 4 illustrates the negotiation probabilities depending on treatment, gender, and job task. We observe that both gender are more likely to negotiate in T2 than in $\mathrm{T} 1$ regardless of the job task. The overall increase in negotiation probabilities is 
similar in both ads (general job ad from $9.6 \%$ to $25.6 \%$; sports ad from $9.3 \%$ to $22.1 \%$ ). Men are slightly less likely than women to negotiate in $\mathrm{T} 1$ for the general job ad whereas men are more likely than women to negotiate in T1 for the sport job ad. In $\mathrm{T} 2$, there are almost no gender differences in negotiation probabilities for the sports ad but some for the general ad (women are more likely to negotiate). These latter findings are in line with the psychological theory on situational moderators (Mischel, 1977) and corroborate survey and laboratory evidence in Bowles et al (2005), which suggests that gender differences in negotiations decrease in environments with low ambiguity.

\section{FIGURE 4 ABOUT HERE}

\section{TABLE 3 ABOUT HERE}

Result 2: Women are not less likely than men to initiate wage negotiations.

\section{Discussion}

Salary negotiations have the potential to crucially determine labor market outcomes, and gender differences in negotiations may be an important cause for existing gender differences in labor market outcomes. One major challenge to better understand the determinants of salary negotiations is that they are difficult to observe in their natural environment. Our approach to lend insights into this issue is to use a natural field experiment that has the ample advantage of observing actual and significant salary negotiations in naturally occurring labor markets without the knowledge of the job market participants.

The experimental set-up allows us to cleanly study whether there are gender differences in the willingness to apply for workplaces with negotiable wages and to initiate wage negotiations by randomizing job-seekers into two treatments. The only difference between these two treatments is whether the job advertisement describes that the wage is negotiable. We study whether this single piece of additional information causes a change in the gender distribution of job applicants and job applicants who initiate salary negotiations.

We report two main findings. First, we find that men prefer workplaces where negotiations are ambiguous, and in such environments they negotiate more than 
women. However, we do find evidence that women are less likely than men to sort out of workplaces where wages are stated to be explicitly negotiable. Second, we observe that there are no statistically significant gender differences in the willingness to negotiate wages. Both findings hold even for a job with a masculine job task, a workplace environment in which one would expect men to be at an advantage. Moreover, we show that these two findings are robust in different labor markets. Thus, our study suggests that the gender gap in wages cannot be universally and easily explained by gender dependent sorting into negotiable workplaces and willingness to initiate wage negotiations.

Our findings may also have important policy implications. We find that simple manipulations of the contract environment can significantly shift the gender composition of the applicant pool. More precisely, by merely adding the information that the wage is 'negotiable' we successfully reduced the gender gap in job applications by approximately $45 \%$. Thus, details of the contract environment have important effects on the gender gap, and with such knowledge public officials can design laws to take advantage of such effects.

One should keep in mind, however, that one particular feature of our experiment is that there is little social interaction between the job-seekers and the employers. This may relieve from gendered social roles and thus help explain why we do not observe strong gender differences as reported in some of the studies in the literature. Indeed, our findings are consistent with meta-analytic research on gender differences in negotiations that suggests that women are at least equally likely to negotiate when communication with other parties is limited (Walters et al, 1998; Stuhlmacher et al, 2007) and other survey evidence that there are no significant gender differences in the willingness to negotiate salaries (Gerhart and Rynes, 1991; O'Shea and Bush, 2002).

More research is necessary to improve our understanding on the role of negotiations in workplaces and how they relate to gender differences in labor market outcomes. For instance, it may be that there gender differences for other labor market negotiations than we observe, such as salary negotiations after initial hire, that may help explain why women earn less than men. In addition, it is entirely possible that women are less likely than men to negotiate wages for other jobs than we advertised or that there are gender differences in negotiation styles and outcomes (Gerhart and Rynes, 1991). 
Our study is only a first attempt at using a natural field experiment to investigate gender differences in the willingness to enter negotiations and negotiable workplaces and to test whether the received results in the literature can be generalized to an environment in which negotiations are not in-person, but over the internet. The roots of this exploration are in the spirit of Mischel (1977), who argued that such context variables crucially and predictably affect (gender) behavior. As modern economies evolve, a greater number of transactions will be completed impersonally; thus, our design permits a glimpse of such interactions in a controlled, natural setting. 


\section{REFERENCES}

Altonji, J. G., and R.Blank. 1999. "Race and Gender in the Labor Market." In Handbook of Labor Economics, Vol. 3C, eds. O. Ashenfelter, and D. Card, 31443259. Amsterdam: Elsevier Science.

Babcock, L., Gelfand, M., Small, D., \& Stayn, H. (2006). "Gender differences in the propensity to initiate negotiations." In D. D. Crèmer, M. Zeelenberg, \& J. K. Murnighan (Eds.), Social psychology and economics (pp. 239-259). Mahwah, NJ: Lawrence Erlbaum.

Babcock, L. and S. Laschever. 2003. Women don't ask: Negotiation and the gender divide. Princeton, NJ: Princeton University Press.

Bertrand, M., and K. F. Hallock. 2001. "The Gender Gap in Top Corporate Jobs." Industrial and Labor Relations Review, 55(1): 3-21.

Beyer, S. (1990). "Gender differences in the accuracy of self-evaluations of performance.” Journal of Personality and Social Psychology, 59(5), 960-970.

Blau, F., and L. M. Kahn. 2000. "Gender Differences in Pay.” Journal of Economic Perspectives, 14(4): 75-99.

Bowles, H. R., Babcock, L., K. L. McGinn. 2005. "Constraints and triggers: Situational mechanics of gender in negotiations." Journal of Personality and Social Psychology 89(6), 951-965.

Eagly, A. H. 1987. Sex Differences in social behavior: A social-role interpretation. Hillsdale, NJ: Erlbaum.

Flory, J.; Leibbrandt, A.and J. A. List (2010). Do Competitive Work Places Deter Female Workers? A Large-scale Natural Field Experiment on Job-Entry Decisions" NBER Working Paper \# 16546.

Gerhart, B., \& Rynes, S. (1991). "Determinants and consequences of salary negotiations by male and female MBA graduates." Journal of Applied Psychology, 76(2), 256-262.

Gneezy, U., Niederle, M., and A. Rustichini. 2003. "Performance in Competitive Environments: Gender Differences.” Quarterly Journal of Economics, 118(3): 1049_ 1074.

Goldin, C. 1990. Understanding the Gender Gap: An Economic History of American Women, New York: Oxford University Press.

Goldin, C., and C. Rouse. 2000. "Orchestrating Impartiality: The Impact of 'Blind' Auditions on Female Musicians.” American Economic Review, 90(4): 715-741. 
Lax, D., and J. Sebenius. 1986. The manager as negotiator: Bargaining for cooperation and competitive gain. New York: Free Press.

Mischel, W. 1977. The interaction of person and situation. In D. Magnusson \& N.S. Endler (Eds.), Personality at the crossroads: Current issues in interactional psychology. Hillsdale, NJ: Erlbaum.

Neale, M. A. and M. H. Bazerman. Cognition and rationality in negotiation. New York: The Free Press.

Niederle, M. and L.Vesterlund. 2007. "Do Women Shy Away From Competition? Do Men Compete Too Much?” Quarterly Journal of Economics, 122(3), 1067-1101.

O'Shea, P.G., and D. F. Bush. 2002. Negotiation for starting salary: Antecedents and outcomes among recent college graduates. Journal of Business and Psychology, $16,365-382$.

Phipps, S., P. Burton, and L.Lethbridge. 2001. 'In and Out of the Labor Market: Long-Term Income Consequences of Child-Related Interruptions to Women's Paid Work." Canadian Journal of Economics, 34(2): 411-29.

Raiffa, H. 1982. The art and science of negotiation. Cambridge, MA: Harvard University Press.

Small, D. A., Gelfand, M., Babcock, L., Gettman, H., 2007. "Who goes to the bargaining table? The influence of gender and framing on the initiation of negotiation." Journal of Personality and Social Psychology 93 (4), 600-613.

Spencer, S. J., Steele, C. M. and D. M. Quinn. 1999. "Stereotype Threat andWomen's Math Performance." Journal of Experimental Social Psychology, 35, 428.

Steele, C. M. 1997. "A threat in the air: How stereotypes shape intellectual ability and performance." American Psychologist 52(6), 613-629.

Stuhlmacher, A. F., and A. E. Walters. 1999. "Gender differences in negotiation outcome: A meta-analysis.” Personnel Psychology 52(3), 653-677.

Stuhlmacher, A. F., M. Citera, and T. Willis. 2007. "Gender differences in virtual negotiation: Theory and research.” Sex Roles 57: 329-339.

Thompson, L. 1998. The mind and heart of the negotiator. Upper Saddle River, NJ: Prentic Hall.

Walters, A. E., A. F. Stuhlmacher, and L. L. Meyer. 1998. "Gender and negotiator competitiveness: A meta-analysis." Organizational Behavior and Human Decision Processes 76(1): 1-29.

Walton, R. E., and R. McKersie. 1965. A behavioral theory of labor negotiations. New York: McGraw Hill. 


\section{FIGURES 1-4}

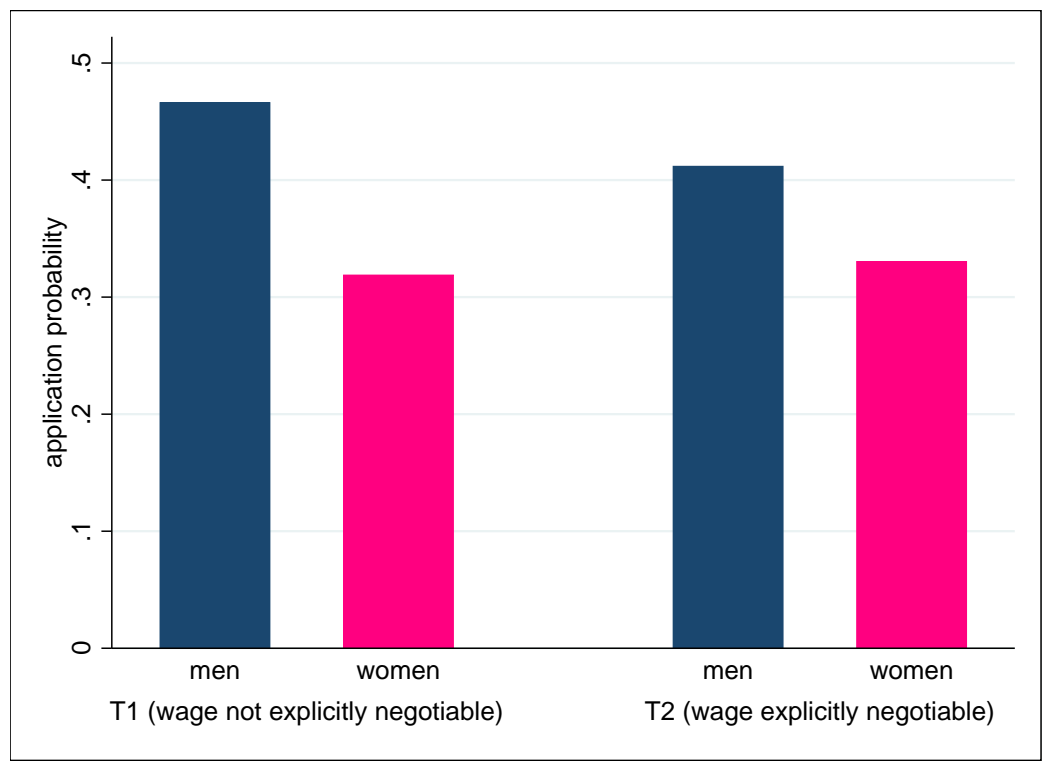

Figure 1: Overall application probabilities depending on treatment and gender.

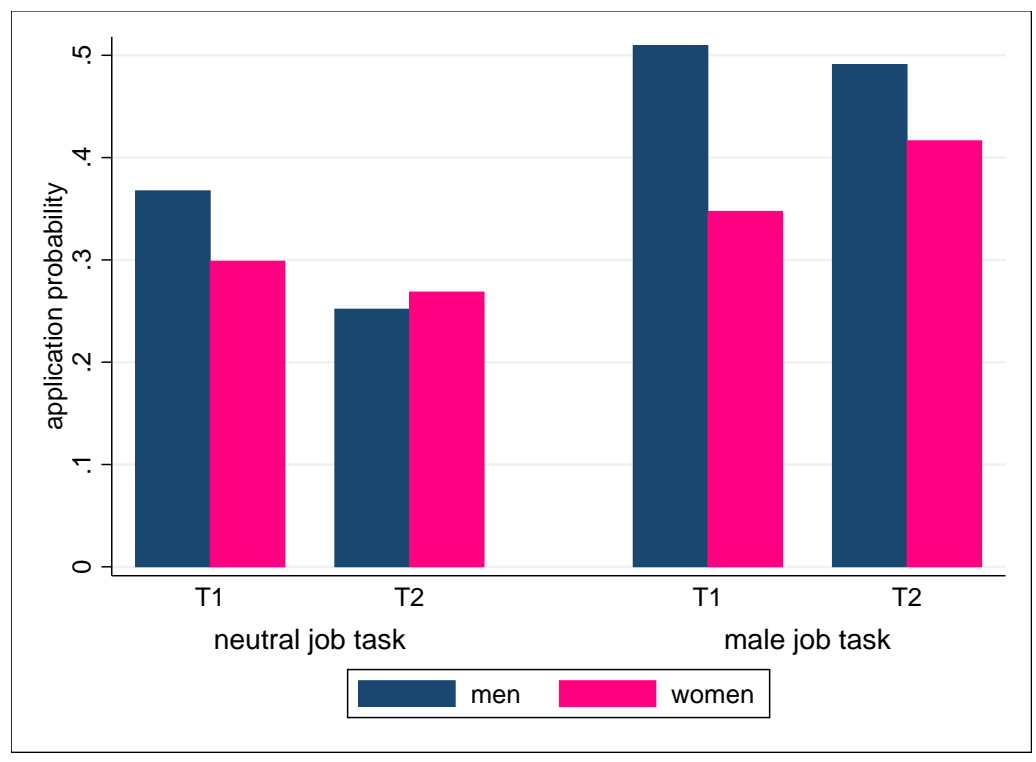

Figure 2: Application probabilities depending on treatment and gender and each of the two job tasks. 


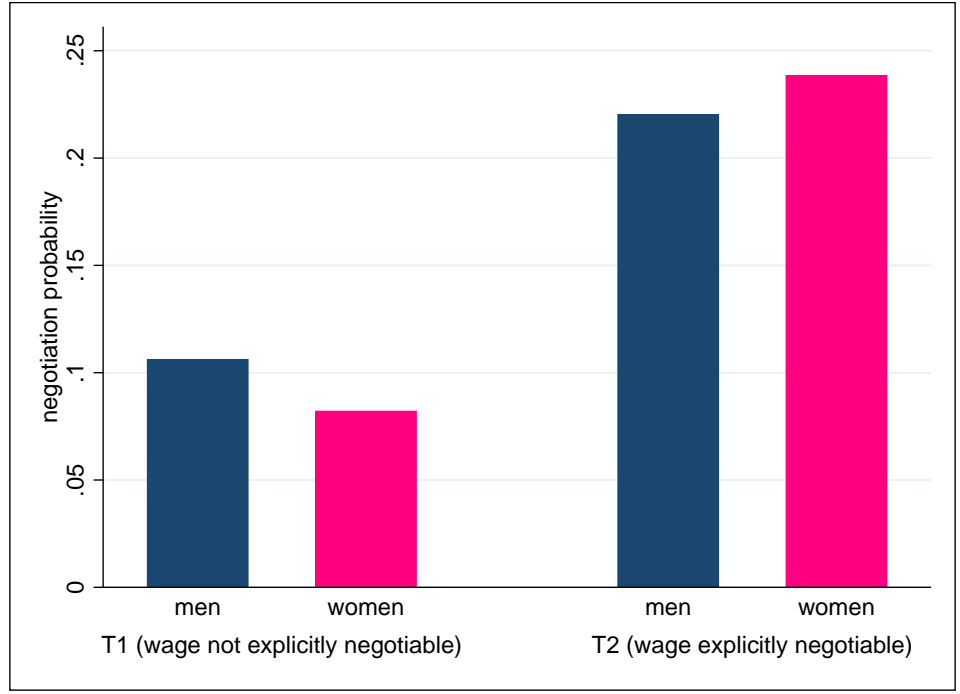

Figure 3: Overall negotiation probabilities depending on treatment and gender.

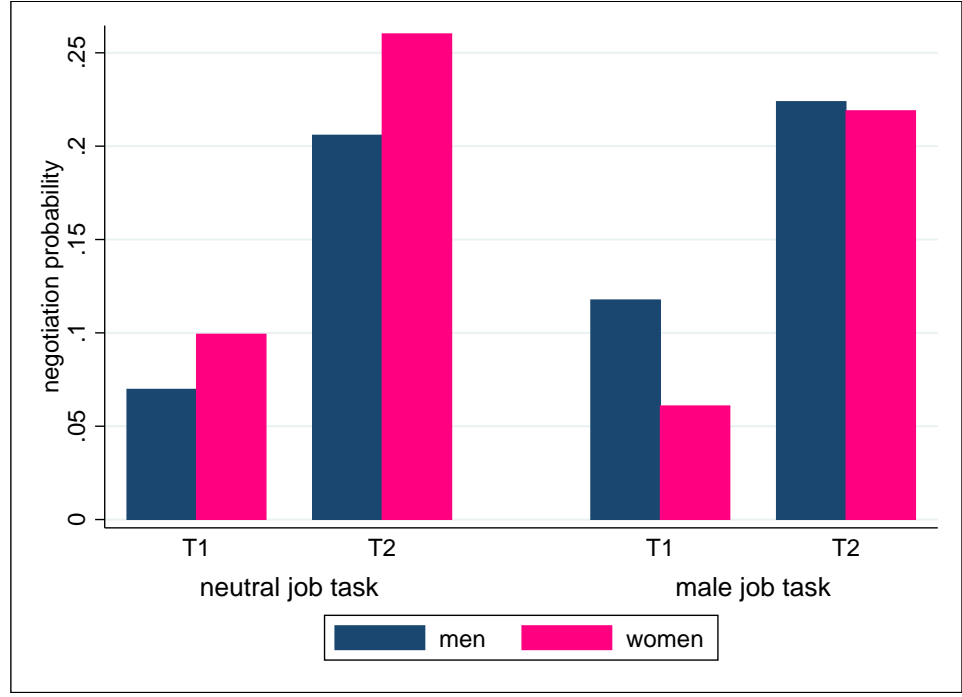

Figure 4: Negotiation probabilities depending on treatment and gender and each of the two job tasks. 
TABLES 1-3

\section{Table 1: Summary of job advertisements}

\begin{tabular}{cccc}
\hline \multirow{2}{*}{ City } & type of job ad & $\begin{array}{c}\text { job-seeker } \\
(\mathrm{N})\end{array}$ & $\begin{array}{c}\text { application } \\
\text { probability }\end{array}$ \\
\hline \multirow{3}{*}{ Atlanta } & administrative & 164 & 0.26 \\
& sports & 207 & 0.39 \\
Dallas & administrative & 68 & 0.18 \\
& sports & 126 & 0.37 \\
Denver & administrative & 153 & 0.35 \\
& sports & 153 & 0.5 \\
Houston & administrative & 158 & 0.3 \\
& sports & 87 & 0.3 \\
Los Angeles & administrative & 114 & 0.35 \\
& sports & 146 & 0.52 \\
Portland & administrative & 110 & 0.32 \\
& sports & 70 & 0.49 \\
San Francisco & administrative & 136 & 0.26 \\
& sports & 150 & 0.47 \\
San Diego & administrative & 66 & 0.35 \\
& sports & 108 & 0.49 \\
& administrative & 213 & 0.25 \\
Washington DC & sports & 153 & 0.4 \\
\hline
\end{tabular}


Table 2: Application probabilities (logit)

Dependent variable: Decision to apply for job (yes or no)

model

T2

Female

T2 $\times$ Female

Male sports task

T2 $\times$ male sports task

Education

T2 $\times$ education

Job experience

(2)

\begin{tabular}{|c|c|c|}
\hline $\begin{array}{l}-0.122^{*} \\
(0.070)\end{array}$ & $\begin{array}{c}-0.208^{\star * *} \\
(0.077)\end{array}$ & $\begin{array}{c}-0.192^{\star *} \\
(0.090)\end{array}$ \\
\hline $0.137^{* * *}$ & $-0.114^{* * *}$ & $-0.107^{* * *}$ \\
\hline (0.028) & $(0.029)$ & $(0.031)$ \\
\hline $0.068^{*}$ & $0.087^{* *}$ & $0.087^{* *}$ \\
\hline \multirow[t]{2}{*}{$(0.041)$} & $(0.041)$ & $(0.044)$ \\
\hline & $0.075^{\star * *}$ & $0.081^{* * *}$ \\
\hline
\end{tabular}

$(0.028)$

$0.100^{* *}$

$(0.030)$

$(0.040)$

$0.117^{* \star *}$

$(0.043)$

$0.061^{* *}$

$(0.029)$

0.016

$(0.042)$

0.011

$(0.017)$

$-0.020$

T2 $\times$ job experience

\begin{tabular}{cccc} 
City fixed effects? & yes & yes & yes \\
\hline $\mathrm{N}$ & 2382 & 2382 & 2116 \\
\hline
\end{tabular}

Notes: ${ }^{* *} p<0.01 ;{ }^{* *} p<0.05 ;{ }^{*} p<0.1$. Coefficients show average marignal effects. Rpbust standard errors in parentheses. Comparison group is T1. Education is a binary variable and 1 if job-seeker has at least a bachelor degree, 0 otherwise. Job experience is a binary variable and 1 if job-seekers has worked before as an administrative assistant, 0 otherwise. 
Table 3: Negotiation probabilities (logit)

Dependent variable: Decision to negotiate wage (yes or no)

model

(2)

(3)

T2

$\begin{array}{ccc}0.046 & 0.045 & 0.010 \\ (0.086) & (0.098) & (0.114) \\ -0.028 & -0.034 & -0.033\end{array}$

Female

$(0.042)$

$(0.042)$

$(0.042)$

T2 $\times$ Female

0.059

0.060

$(0.042)$

(0.052)

$(0.053)$

0.061

Male sports task

$-0.023$

(0.053)

$(0.043)$

$-0.018$

T2 $\times$ male sports task

0.001

(0.053)

$-0.020$

$(0.055)$

Education

T2 $\times$ education

Job experience

T2 $\times$ job experience

\begin{tabular}{cccc} 
City fixed effects? & yes & yes & yes \\
\hline $\mathrm{N}$ & 863 & 863 & 805 \\
\hline
\end{tabular}

Notes: ${ }^{* * *} p<0.01 ;{ }^{* *} p<0.05 ;{ }^{*} p<0.1$. Coefficients show average marignal effects. Rpbust standard errors in parentheses. Comparison group is T1. Education is a binary variable and 1 if job-seeker has at least a bachelor degree, 0 otherwise. Job experience is a binary variable and 1 if job-seekers has worked before as an administrative assistant, 0 otherwise. 


\section{APPENDIX FIGURES A-B}

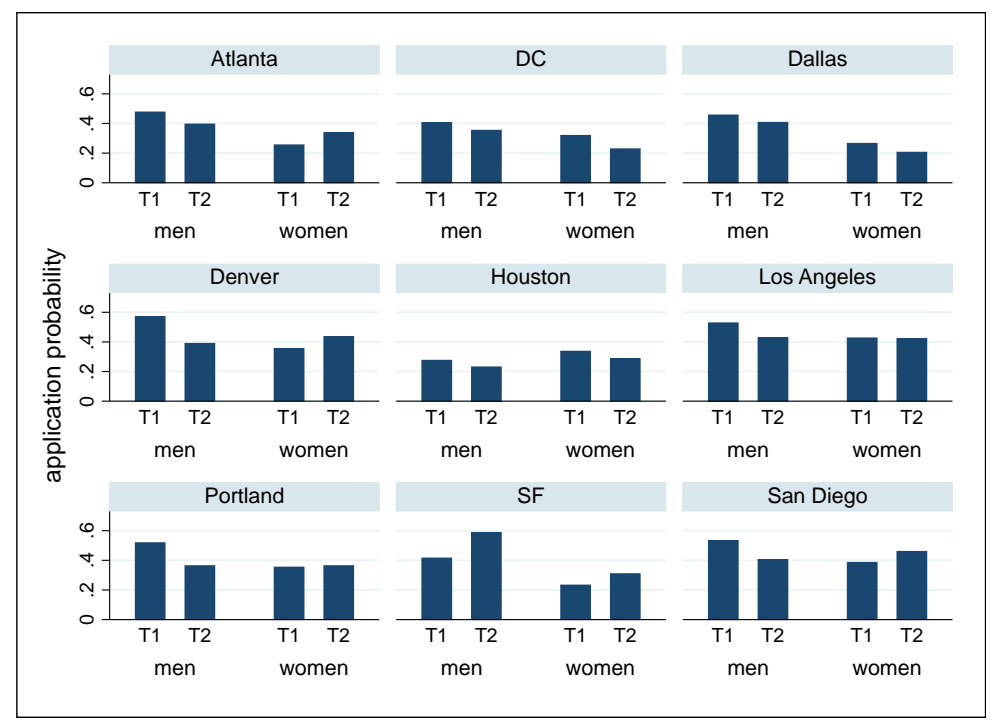

Figure A: Application probabilities depending on treatment and gender shown for each city in which job ads were placed.

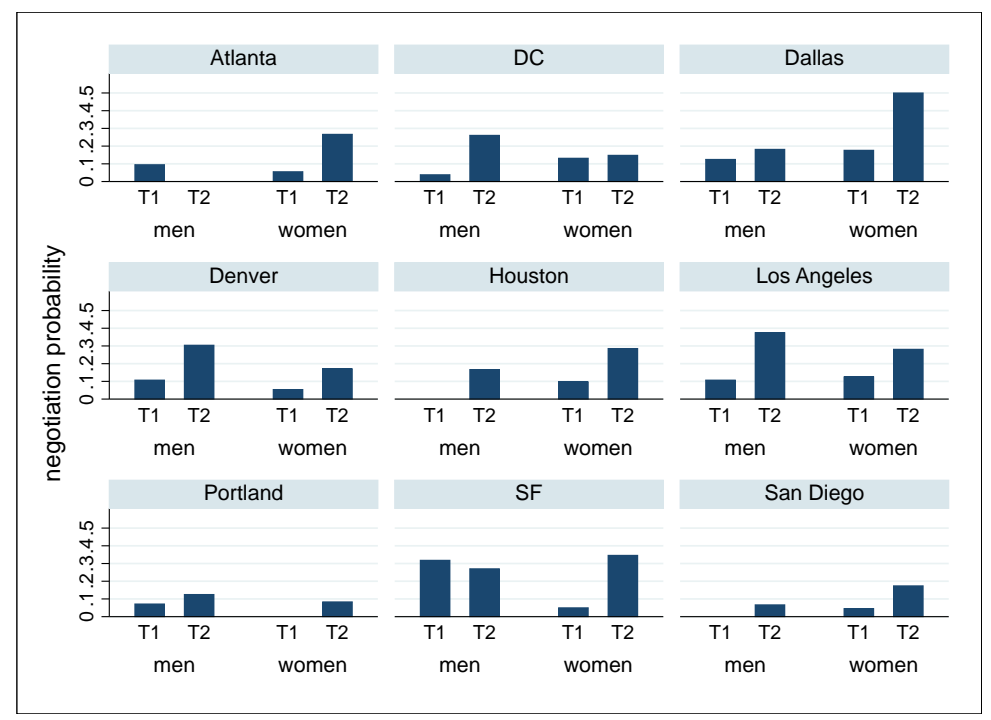

Figure B: Negotiation probabilities depending on treatment and gender shown for each city in which job ads were placed. 


\section{APPENDIX A}

\section{i.) GENERAL JOB ADVERTISEMENT}

Posting Category: admin/office jobs

Title: Administrative Assistant ${ }^{9}$

The [...] is seeking a [city name]-area administrative assistant to help[with fundraising. Responsibilities for the available positions include fundraising campaigns development and marketing needs identification. The successful candidates will also be comfortable with typical administrative duties - light correspondence, proofreading, filing, email and phone communication, etc.

If you are interested, please email us your CV or resume, attention: Name

Name

Affiliation

Address

Compensation: Hourly

Location: [city name]

\section{ii.) SPORTS JOB ADVERTISEMENT}

Posting Category: Admin/Office Jobs

Title: Sports News Assistant

The [...] is seeking a [enter city name]-area administrative assistant to help gather information on sports stories. The assistant will provide us with upto-date information on local news and views on basketball, football, baseball, soccer, Nascar, golf, tennis, hockey, and other sports. Responsibilities for the available positions include reading local sports-related news coverage (pro-, semi-pro, and college), and preparing short reports. The successful candidates will also be comfortable with typical administrative duties - light correspondence, proofreading, filing, email and phone communication, etc.

If you are interested, please email us your CV or resume, attention: Name

Name

Affiliation

Address

Compensation: Hourly

Location: [city name]

\footnotetext{
${ }^{9}$ Please see Appendix B. In Dallas and San Diego the title was "Marketing Assistant".
} 


\section{iii.) Response to job-seekers who signaled interest (treatment T1 and T2)}

Thank you for your interest in the position.

We are sending this general first response to interested applicants. We apologize if you have any unanswered questions. If you still have questions about the position, please send them, along with your response to the enclosed interview questions to complete your application.

First, a little more information about the job:

The hours are flexible. You are able to work from home.

T1: The position pays $\$ 17.6$ per hour. ${ }^{10}$

T2: The position pays $\$ 17.6$ per hour. But the applicant can negotiate a higher wage.

$$
\text { OR }
$$

The position pays $\$ 17.6$ per hour/ negotiable.

If you are interested, please answer the attached interview questions, and return it back to us. Please also include your CV or resume (if not already sent), and any remaining questions you have about the position, along with your answers to the interview questions.

Best Regards,

Name, Affiliation, Address

\section{iv.) Interview questions}

Please answer the following questions with a few sentences each.

1.Please describe why you are interested in this position.

2. Does the wage meet your expectations? Please quantify your desired wage.

\section{v.) Response for job-seekers who have applied}

Thank you for your CV and your responses to the interview questions. We will be contacting candidates that are a good fit within the next weeks.

Name, Affiliation, Address

\footnotetext{
${ }^{10}$ Please see Appendix B - in two ads we posted different wages.
} 


\begin{abstract}
APPENDIX B
In the main text we presented data from all job ads for administrative office jobs that we have posted. In this appendix we exclude job ads that may be considered as pilot job ads. We show below that excluding subjects from these job ads from our analysis leads to the same (but more pronounced) Finding 1 and the same Finding 2.

We posted four job ads that are different on possibly important dimensions: wages offered, treatment description, title of job ad and interview questions. The four job ads were the general job ads in Dallas, Atlanta, San Diego, and Houston.

More precisely, the general job ad in Dallas offered a wage of \$13.2/hour instead of $\$ 17.6 /$ hour. The general job ad in Atlanta offered a wage of $\$ 15 /$ hour instead of \$17.6/hour. Both of these ads and the general job ad in San Diego had also four instead of two interview questions. The treatment description in T2 for the general job ad in Houston differed from all other T2 descriptions for general job ads. In Houston, the description was “The position pays $\$ 17.6$ per hour. But the applicant can negotiate a higher wage.” In the other cities, the general job ad description was “The position pays \$17.6 per hour/ negotiable.”

Excluding job-seekers from these four job ads reduces our sample with identifiable gender from $\mathrm{N}=2382$ to $\mathrm{N}=1926$. Figure $\mathrm{C}$ corresponds to Figure 1 and shows the application probabilities depending on treatment and gender without the pilot job ads. Figure D corresponds to Figure 3 and show the negotiation probabilities depending on treatment and gender without the pilot job ads. Table A corresponds to Table 2, and Table B to Table 4.

We find that excluding the pilot job ads leads to a somewhat sharper finding 1 . In particular, we can see in Table A that the T2 $\mathrm{x}$ gender interaction is now significant at $\mathrm{p}<0.034$ in all three models. The coefficients are substantially larger in the restricted sample $(9.5-10.4 \%)$ than in the sample including the pilots $(6.2-8.7 \%)$. The content of finding 2 remains identical. We can see in Table $\mathrm{B}$ that the $\mathrm{T} 2 \mathrm{x}$ gender interaction is equally statistically insignificant at $\mathrm{p}>0.223$ ( $>0.252$ full sample) and that the coefficients are similar in the restricted sample $(5.5 \%-6.8 \%)$ as in the sample including the pilots (5.9-6.1\%).
\end{abstract}




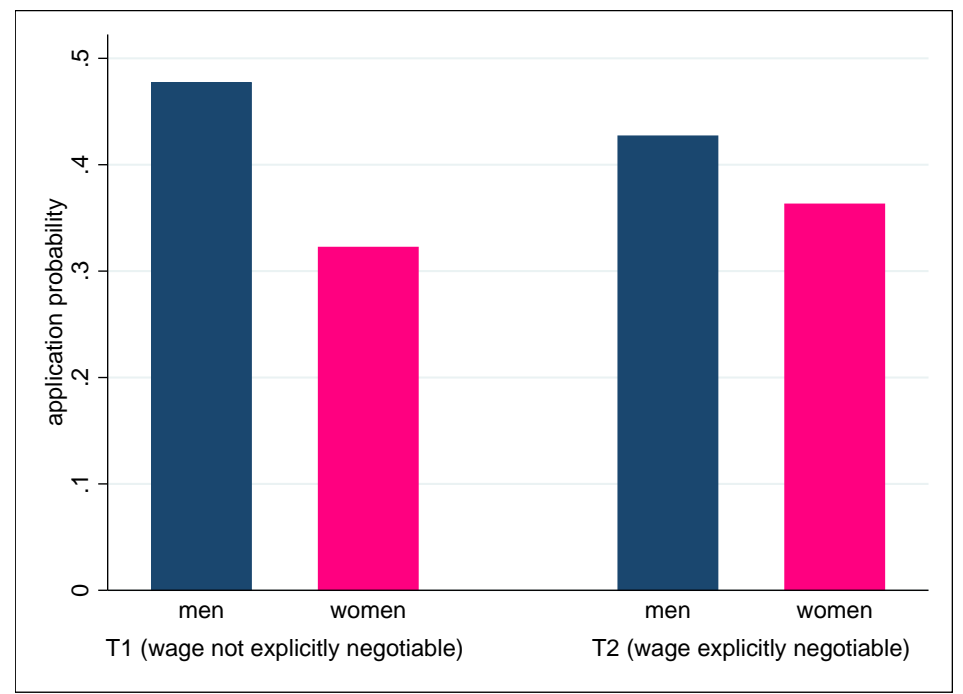

Figure C: Overall application probabilities depending on treatment and gender without pilot job ads.

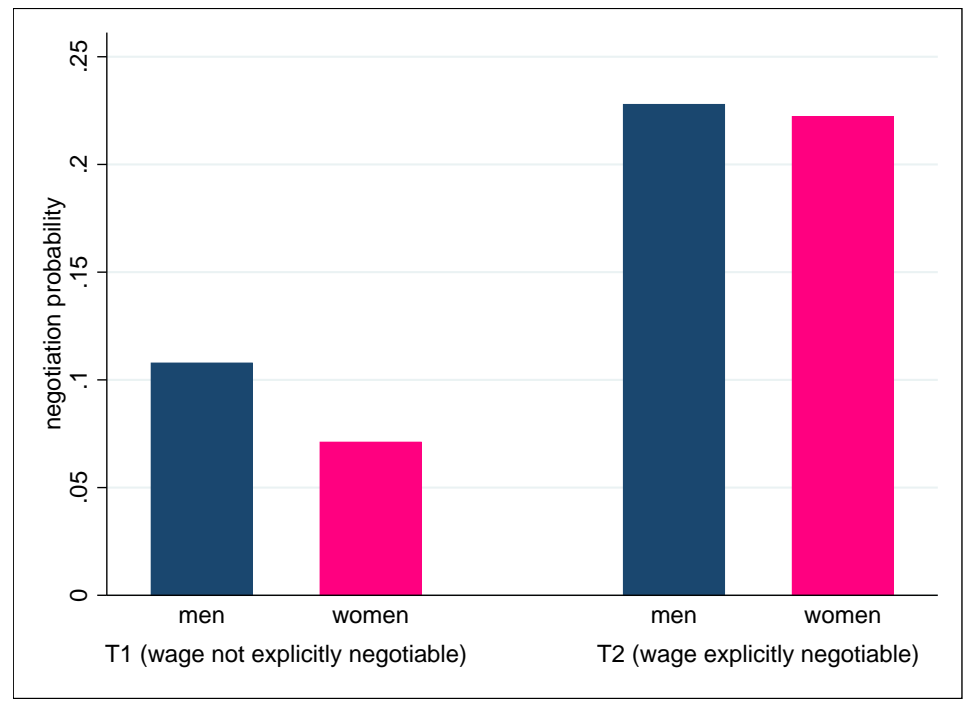

Figure D: Overall negotiation probabilities depending on treatment and gender without pilot job ads. 
Table A: Application probabilities without pilot (logit)

Dependent variable: Decision to negotiate wage (yes or no)

model

T2

Female

T2 $\times$ Female

Male sports task

T2 $\times$ male sports task

Education

T2 $\times$ education

Job experience

T2 $\times$ job experience
(1)

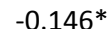

$$
\text { (0.075) }
$$

$-0.151^{* * *}$

(0.031)

$0.095^{* *}$

(0.045)

(2)

(3)

$-0.213 * * \quad-0.193 *$

$(0.085) \quad(0.098)$

$-0.129 * * * \quad-0.114 * * *$

(0.032) (0.034)

$0.104^{* *} \quad 0.103^{* *}$

(0.045) (0.048)

$0.106^{* * *} \quad 0.110^{* * *}$

(0.035) (0.037)

$0.080 * \quad 0.092 *$

(0.046) (0.050)

$0.076 * *$

(0.033)

0.030

(0.047)

0.018

$(0.020)$

$-0.024$

(0.028)

yes

1926

yes

1926

yes

Notes: ${ }^{* * *} p<0.01 ;{ }^{* *} p<0.05 ;{ }^{*} p<0.1$. Coefficients show average

marignal effects. Rpbust standard errors in parentheses. Comparison group is T1. Education is a binary variable and 1 if job-seeker has at least a bachelor degree, 0 otherwise. Job experience is a binary variable and 1 if job-seekers has worked before as an administrative assistant, 0 otherwise.

Table B: Negotiation probabilities without pilot (logit)

Dependent variable: Decision to negotiate wage (yes or no)

$\begin{array}{cccc}\text { model } & (1) & (2) & (3) \\ & & & \\ \text { T2 } & 0.035 & 0.042 & 0.031 \\ & (0.088) & (0.107) & (0.126) \\ \text { Female } & -0.054 & -0.051 & -0.041 \\ & (0.046) & (0.046) & (0.045) \\ 2 \times \text { Female } & 0.068 & 0.067 & 0.055 \\ & (0.056) & (0.057) & (0.057)\end{array}$

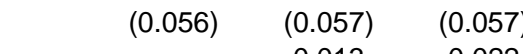

Male sports task $\quad 0.013 \quad 0.022$

$\begin{array}{lll} & (0.052) & (0.054) \\ \text { T2 } \times \text { male sports task } & -0.007 & -0.019\end{array}$

$(0.062) \quad(0.065)$

Education $\quad 0.067$

$(0.050)$

0.020

$(0.060)$

T2 $\times$ education

$\begin{array}{lc}\text { Job experience } & 0.037 \\ & (0.025)\end{array}$

T2 $\times$ job experience 0.019

$(0.031)$

$\begin{array}{cccc}\text { City fixed effects? } & \text { yes } & \text { yes } & \text { yes }\end{array}$

Notes: ${ }^{* * *} p<0.01 ;{ }^{* *} p<0.05 ;{ }^{*} p<0.1$. Coefficients show average 692

marignal effects. Rpbust standard errors in parentheses. Comparison group is $\mathrm{T} 1$. Education is a binary variable and 1 if job-seeker has at least a bachelor degree, 0 otherwise. Job experience is a binary variable and 1 if job-seekers has worked before as an administrative assistant, 0 otherwise. 